\title{
АРМИРОВАНИЕ НАСЫПЕЙ ВНУТРИПРОМЫСЛОВЫХ АВТОМОБИЛЬНЫХ ДОРОГ НА СЛАБОМ ОСНОВАНИИ КАК РЕШЕНИЕ ПО СНИЖЕНИЮ ВЕЛИЧИНЫ ОСАДКИ ЗЕМЛЯНОГО ПОЛОТНА
}

\author{
Еременко Евгений Сергеевич1, \\ eseremenko@rnntc.ru
}

\author{
Галич Николай Николаевич1, \\ nngalich@rnntc.ru
} Кузьмин Дмитрий Андреевич1,
dakuzmin@rnntc.ru

\author{
Мелентьев Александр Сергеевич1, \\ asmelentev@rnntc.ru \\ 1 OОО «НК «Роснефрть-НТЦ», \\ Россия, 350000, г. Краснодар, ул. Красная, 54.
}

\begin{abstract}
Актуальность исследования обусловлена необходимостью устройства земляного полотна, в том числе и земляного полотна внутрипромысловых автомобильных дорог на территории ПАО «НК Роснефрть», общая протяженность которых составляет несколько тысяч километров, в сложных инженерно-геологических условиях. Нужно отметить появление огромного ассортимента геотекстильных армирующих материалов, использование которых является эфффективным способом решения проблемы снижения осадки насыпей земляного полотна, что должно привести и приводит, в свою очередь, к оптимизации средств.

Цель: оптимизация затрат на строительство автомобильных дорог на слабом основании за счет армирования насыпей местными или геосинтетическими материалами.

объект: насыпь земляного полотна.

Предмет: осадочные явления грунта земляного полотна на слабом основании в зависимости от типа укрепления.

Методы: ретроспективный анализ и метод сравнения. Расчет осадки выполнялся методом послойного суммирования, для

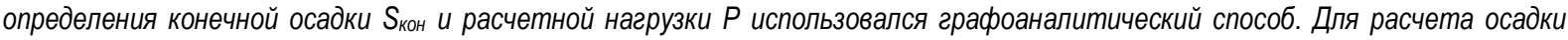
насыпи с учетом армирования земляного полотна лежневым настилом или георешеткой также применялся метод математического моделирования

Результаты. Приведены расчеты обоснования перспективности применения альтернативньх материалов при укреплении земляного полотна на слабом основании. Для подтверждения получения экономической эфрфективности от предлагаемых решений проведено технико-экономическое сравнение двух вариантов армирования конструкции земляного полотна: лежневым настилом и георешеткой - с моделью земляного полотна, построенного по классической технологии. Определен экономический эфффект от армирования земляного полотна на слабом основании.
\end{abstract}

\section{Ключевые слова:}

Земляное полотно, конструкции укрепления земляного полотна, лежневый настил, георешетка, максимальное напряжение, степень устойчивости насыпи, конечная осадка насыпи.

\section{Введение}

Метод армирования земляного полотна на слабых грунтах известен уже более 50 лет. Теоретические основы метода были разработаны во Франции в 1966 г. А. Видалем и Ф. Шлоссером. В дальнейшем многие ученые и исследователи, как иностранные, так и отечественные, развивали данное направление [1, 6-20]. Научные разработки в этой отрасли, безусловно, актуальны в связи с необходимостью устройства земляного полотна, в том числе и земляного полотна внутрипромысловых автомобильных дорог на территории ПАО «НК Роснефть», в сложных инженерногеологических условиях. При этом общая протяженность автомобильных дорог составляет несколько тысяч километров. Необходимо также отметить появление на рынке огромного ассортимента геотекстильных армирующих материалов, использование которых является современным эффективным способом решения проблемы повышения надежности работы земляных сооружений, в том числе и вопроса снижения осадки насыпей земляного полотна, что должно привести и приводит, в свою очередь, к оптимизации средств за счет уменьшения объемов земляных работ.

При использовании слабых грунтов в основании земляного полотна возникают деформации насыпи. При некоторых условиях эти деформации могут иметь катастрофический характер и приводить к разрушению насыпи с выдавливанием слабого грунта по бокам в валы выпирания [2, 6-20]. Опыт строительства и содержания внутрипромысловых автомобильных дорог показал, что выдавливание грунта приводит к разрушению или к длительным и неравномерным просадкам, трудно прогнозируемым по времени. Можно, однако, отметить, что данный процесс носит затухающий характер, в связи с чем существует принципиальная возможность учесть возможность деформации земляного полотна в результате уплотнения. 
В рамках определения перспективности применения альтернативных материалов для армирования земляного полотна в Специализированном Институте по Транспортной Инфраструктуре ПАО «НК Роснефть» было проведено исследование влияния армирующего материала на конечную осадку насыпи.

Основной целью данного исследования являлось понимание возможности оптимизации капитальных затрат на строительство внутрипромысловых автомобильных дорог на слабом основании за счет армирования насыпей местными (лежневый настил) или геосинтетическими материалами. Было выполнено сравнение двух вариантов армирования конструкции земляного полотна: лежневым настилом и георешеткой с моделью без армирования; был определен экономический эффект от применения армирования земляного полотна на слабом основании. Рассматривались такие критерии, как максимальное напряжение, степень устойчивости насыпи, стоимость возведения. Было предложено методическое обоснование для исследования применения альтернативных материалов для армирования земляного полотна и определения конечной осадки насыпи. В данной статье приводятся результаты применения армирующих материалов при укреплении земляного полотна на слабом основании в периметре деятельности ПАО «НК «Роснефть».

\section{Расчет конечной осадки насыпи} на слабом основании без армирования

Для насыпи земляного полотна (рис. 1), выполненной из грунта плотностью $1,989 \mathrm{~T} / \mathrm{m}^{3}$, в соответствии с [3, 4], выполним расчет конечной осадки насыпи. При этом слабое основание сложено торфом мощностью 4,10 м, слой торфа подстилает супесь полутвердой консистенции, а горизонт грунтовых вод совпадает с поверхностью земли.

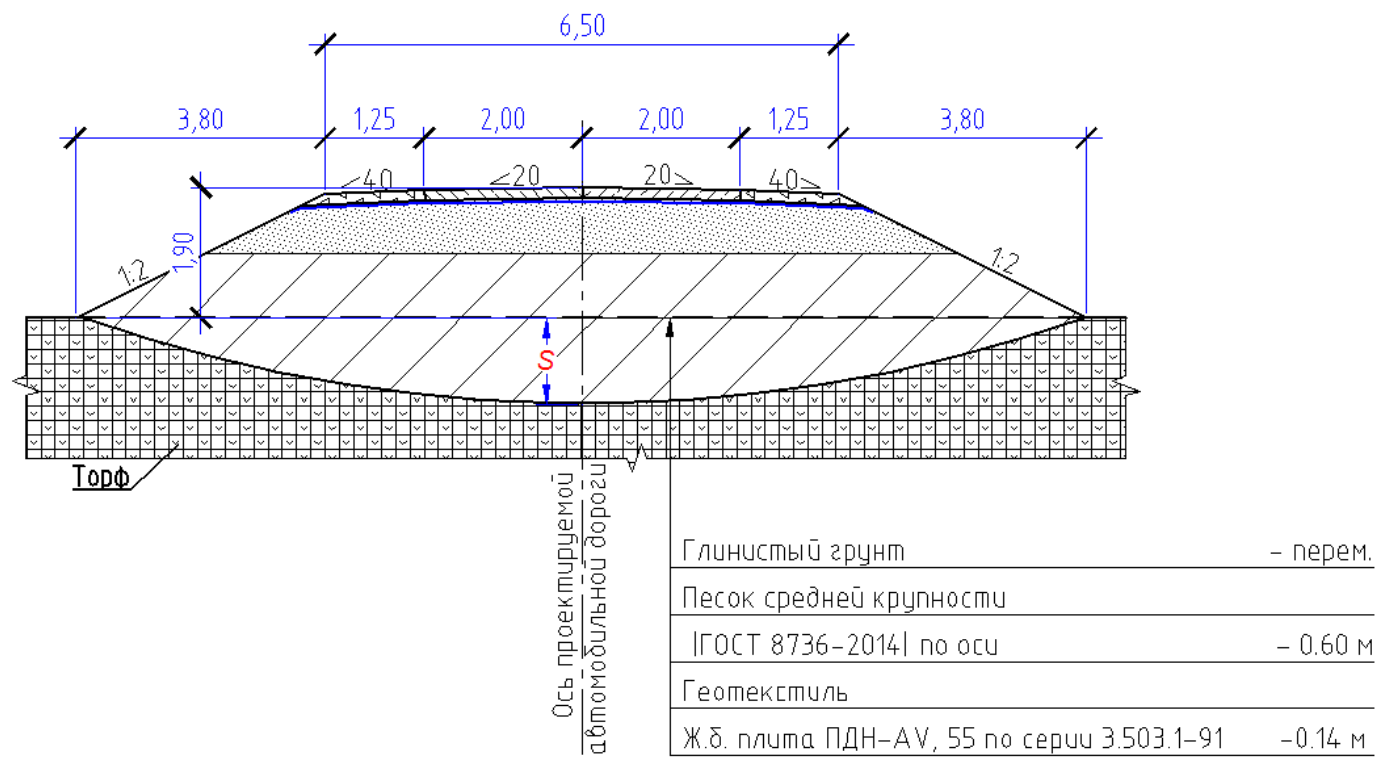

Рис. 1. Расчетная схема насыпи

Fig. 1. Fill design diagram

Конечную осадку исходя из условий одномерной задачи определяем методом послойного суммирования по формуле

$$
S=0,001 \sum_{1}^{n} e_{p z i} \cdot H_{i} .
$$

Расчетную нагрузку от насыпи на поверхности слабой толщи определяем по формуле

$$
P=\gamma_{\mathrm{H}} \cdot h_{\mathrm{H}} \text {. }
$$

Конечная осадка $S_{\text {кон }}$ и расчетная нагрузка $P$ определяются графоаналитическим способом: построение графиков $P=f(S), S=f(P)$, определение точки пересечения двух графиков. В итоге $S_{\text {кон }}=1,15$ м, $P=0,038$ МПа.

Конечная осадка насыпи на слабом торфяном основании, возведенной без применения армирующих материалов, составляет $1,15 \mathrm{~m}$.

Следующим этапом стало исследование влияния на конечную осадку насыпи применения лежневого настила в качестве армирующего материала.
Расчет конечной осадки насыпи, армированной лежневым настилом

На рис. 2 приведена расчетная схема насыпи, армированной лежневым настилом.

Для сосново-пушицевого торфа со степенью разложения $50 \%$, удельным сопротивлением сжатию единицы площади торфяного основания 0,315 кгс/ $\mathrm{cm}^{2}$, силой сопротивления срезу, отнесенной на 1 см длины периметра штампа, 6,64 кгс/см в соответствии с [5] выполним расчет конечной осадки насыпи. Торф с вышеуказанными параметрами характерен, согласно данным инженерно-геологических изысканий, для района расположения объектов транспортной инфраструктуры ООО «РН-Уватнефтегаз» (дочернего общества ПАО «НК «Роснефть»).

Несущую способность торфяной залежи при ширине дороги 6,5 м и однократном загружении определяем по формуле:

$$
P_{0}=A_{0}+B_{0} \frac{\Pi}{S}
$$




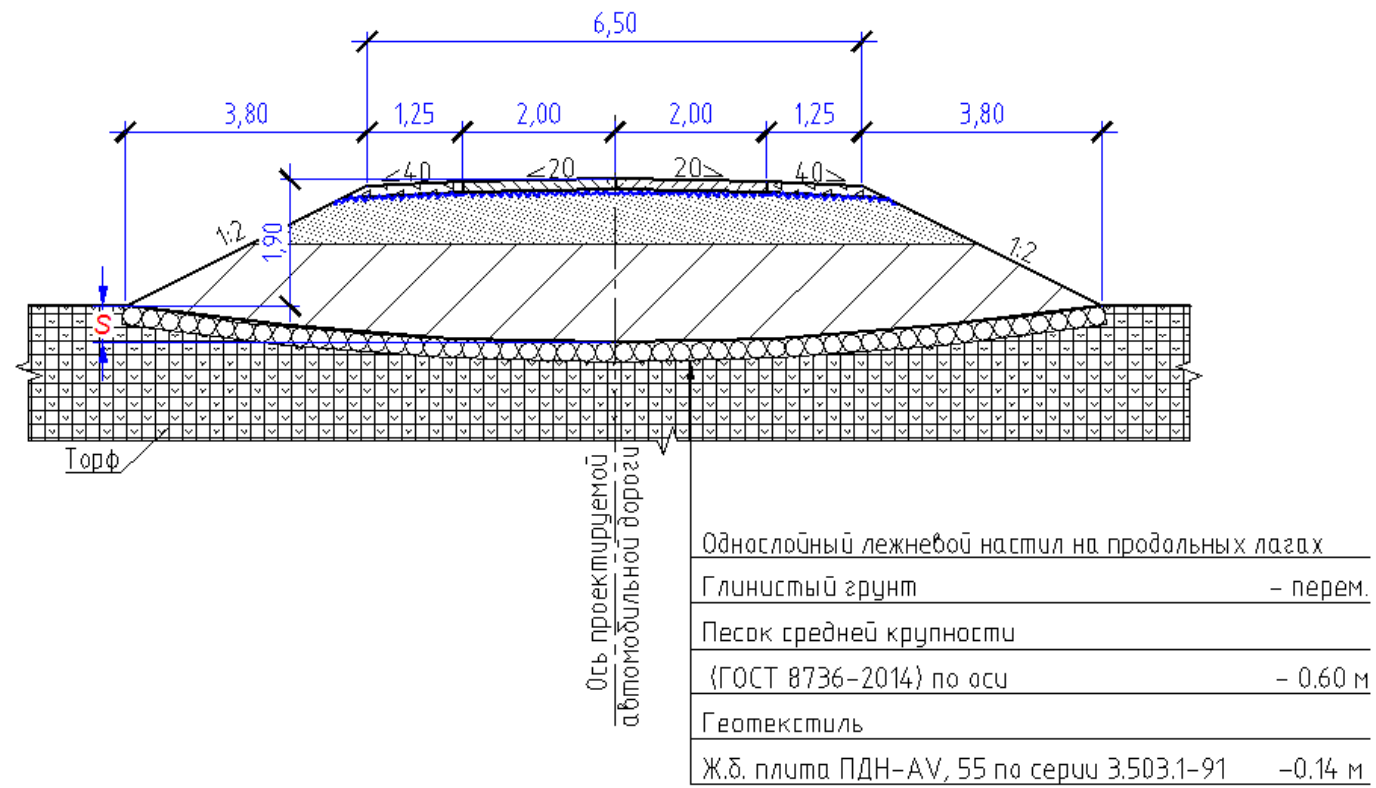

Рис. 2. Расчётная схема насыпи, армированной лежневым настилом

Fig. 2. Design scheme of the embankment reinforced by the bed flooring

Удельное давление собственного веса насыпи на основание вычисляем по формуле:

$$
P=\frac{F}{S} \text {. }
$$

Осадку основания $\mathrm{S}$ при длительном загружении определяем по формуле:

$$
S=\lambda_{\max } \cdot \varphi(H) \cdot f(P) .
$$

Для среднеразложившегося торфа коэффициент $\lambda_{\max }$ вычисляем по формуле:

$$
\lambda_{\max }=\frac{\omega-185}{63+\omega} .
$$

Коэффициенты $\varphi(H)$ и $f(P)$ определяем по графику зависимости осадки от мощности торфяной залежи и графику зависимости осадки от нагрузки соответственно.
В итоге конечная осадка основания составляет $S=0,77$ м.

Расчет подтверждает исполнительная съемка, а также результаты мониторинга, выполненного на объектах $\mathrm{OOO}$ «РН-Уватнефтегаз» (дочернее общество ПАО «НК «Роснефть»).

Следовательно, применение лежневого настила позволяет уменьшить осадку насыпи на величину до $30 \%$.

В целях оптимизации нижняя часть насыпи (толщиной 0,3 м) на болотах отсыпается из маловлажного торфа. Частичная замена минеральных грунтов торфом позволяет сократить объем привозного минерального грунта. При этом верхняя часть насыпи попрежнему выполняется из песчаных или глинистых грунтов. Конструкция земляного полотна с конструктивным слоем из торфа приведена на рис. 3 .

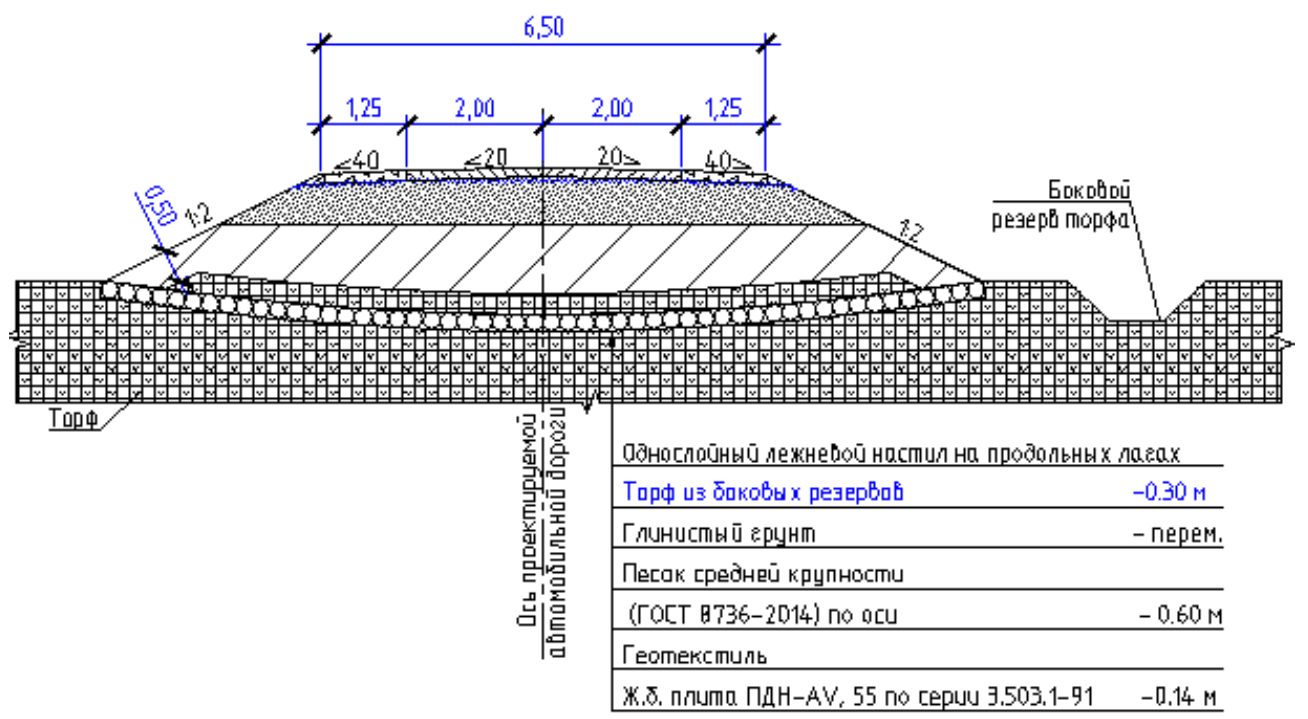

Pис. 3. Конструкиия земляного полотна с конструктивным слоем из торфа

Fig. 3. Structure of roadbed with peat structural layer 
При правильном конструировании и технологии работ обеспечивается необходимая прочность земляного полотна. В разработанной конструкции минеральный грунт над торфяным слоем на откосах толщиной 0,50 м исключает боковое выдавливание, слой торфа подвергнется компрессионному сжатию под весом насыпи.

Осадка торфяного слоя определяется по формуле:

$$
S=0,001 \cdot l_{p} \cdot H_{p},
$$

где $l_{p}$ - модуль осадки, $H_{p}$ - толщина торфяного слоя, м.
В результате расчета получено, что торфяной слой сожмётся на 8 см без бокового выдавливания. Мощность слоя торфа до консолидации - 0,38 м, после консолидации - 0,30 м.

Следующим этапом стало исследование влияния на конечную осадку насыпи применения георешетки в качестве армирующего материала.

\section{Расчет конечной осадки насыпи,} армированной георешеткой

На рис. 4 приведена расчетная схема насыпи, армированной георешеткой.

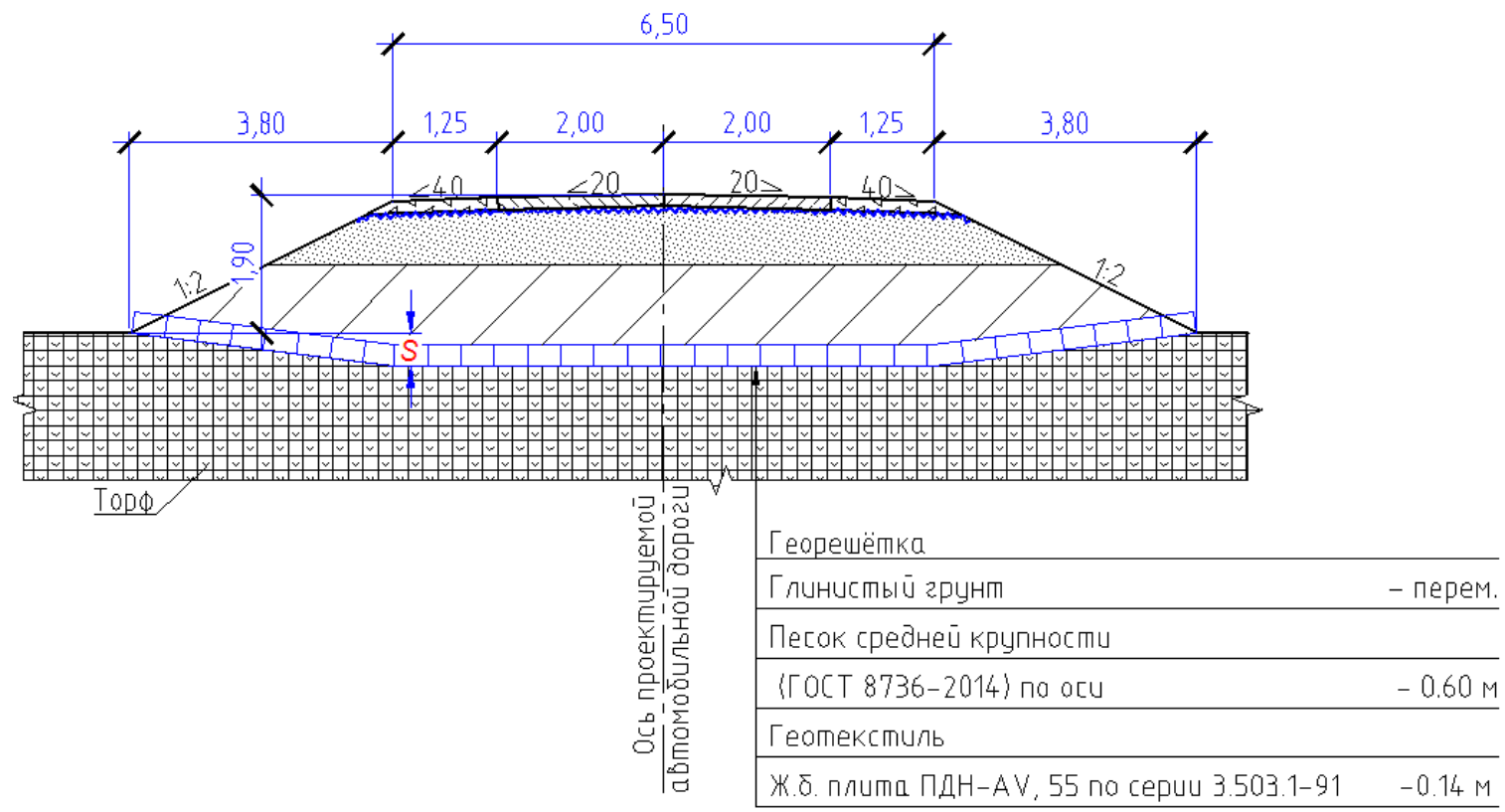

Pис. 4. Расчетная схема насыпи, армированной георешеткой

Fig. 4. Design scheme of embankment reinforced with geogrip

Исходные данные для расчетов: высота георешетки - 15 см; ячейка - $20 \times 20$ см.

Осадка основания насыпи с учётом работы георешетки определяется по формуле:

$$
S_{0}=S-2 \mathrm{C}_{1} \beta,
$$

где $S$ - осадка насыпи без армирования; $C_{1}-$ модуль упругости георешетки; $\beta$ - коэффициент условий работы георешетки.

Осадка основания равна $S=0,52$ м.

Следовательно, применение георешетки позволяет уменьшить осадку насыпи на $55 \%$.

И в этом варианте армирования земляного полотна рекомендуется нижнюю часть насыпи (толщиной 0,3 м) отсыпать из маловлажного торфа. При этом при правильном конструировании и технологии работ обеспечивается необходимая прочность земляного полотна. Минеральный грунт над торфяным слоем на откосах толщиной 0,50 м исключает боковое выдавливание, слой торфа подвергнется компрессионному сжатию под весом насыпи.

Для подтверждения получения экономического эффекта от предложенных решений произведем технико-экономическое сравнение конструкций земляного полотна на слабом основании.
Технико-экономическое сравнение конструкций земляного полотна на слабом основании

В таблице приведено технико-экономическое сравнение конструкций земляного полотна на слабом основании, определен экономический эффект на 10 км автомобильной дороги.

В результате технико-экономического сравнения конструкций земляного полотна выявлено, что наиболее выгодно использование в качестве проектного решения лежневого настила и торфа в теле насыпи. Экономия составила $9 \%$ за счет уменьшения объема привозного грунта и как следствие уменьшения транспортных расходов.

\section{Заключение}

1. Технико-экономическое сравнение конструкций земляного полотна на слабом основании показало, что наиболее целесообразно использование в качестве проектного решения лежневого настила и торфа в теле насыпи. За счет уменьшения объема привозного грунта экономия составила 9 \%. Мониторинг, выполненный на объектах ООО «РНУватнефтегаз» (дочернее общество ПАО «НК «Роснефть»), подтвердил, что применение лежне- 
вого настила позволяет уменьшить осадку насыпи на величину до $30 \%$

2. С целью оптимизации объема земляных работ рекомендуется нижнюю часть насыпи (толщиной 0,3 м) отсыпать из местного маловлажного торфа, при этом с целью обеспечения устойчивости основания на откосах предусматривать слой минерального грунта толщиной 0,50 м над торфяным слоем.

Таблица. Технико-экономическое сравнение конструкиий земляного полотна на слабом основании

Table. Technical and economic comparison of structures of the roadbed on a weak base

\begin{tabular}{|c|c|c|c|}
\hline \multirow[b]{2}{*}{$\begin{array}{l}\text { Вид работ } \\
\text { Work type }\end{array}$} & \multicolumn{3}{|c|}{ Стоимость, тыс. p./Cost, ths. rub. } \\
\hline & $\begin{array}{c}\text { Насыпь без арми- } \\
\text { рования } \\
\text { Bulk without } \\
\text { reinforcement } \\
\end{array}$ & $\begin{array}{c}\text { Насыпь, армированная лежневым } \\
\text { настилом, с прослойкой торфа } \\
\text { Bed-reinforced bulk with peat } \\
\text { interlayer }\end{array}$ & $\begin{array}{l}\text { Насыпь, армированная георе- } \\
\text { шеткой, с прослойкой торфа } \\
\text { Georestick reinforced bulk } \\
\text { with peat interlayer }\end{array}$ \\
\hline $\begin{array}{l}\text { Устройство земляного полотна (в т. ч. } \\
\text { устройство лежневого настила и георешетки) } \\
\text { Gravework arrangement (incl. underfloor and } \\
\text { geo-nut arrangement) }\end{array}$ & 167340 & 124520 & 124530 \\
\hline $\begin{array}{l}\text { Устройство дорожной одежды } \\
\text { Construction of road clothing }\end{array}$ & 340990 & 340990 & 340990 \\
\hline $\begin{array}{l}\text { Устройство искусственных сооружений } \\
\text { Construction of artificial structures }\end{array}$ & 43989 & 43989 & 43989 \\
\hline Транспортные расходы/Transportation costs & 176692 & 152994 & 188347 \\
\hline Итог/Total & 729011 & 662493 & 697856 \\
\hline Выгода, тыс. p./Benefit, ths. rub. & - & 66518 & 31155 \\
\hline Выгода/Benefit, \% & - & 9 & 4 \\
\hline
\end{tabular}

\section{СПИСОК ЛИТЕРАТУРЫ}

1. Семендяев Л.И. Методика расчета насыпей, армированных различными материалами. - Бронницы.: УНР-494, 2001. - 46 с.

2. Евгеньев И.Е., Казарновский В.Д. Земляное полотно автомобильных дорог на слабых грунтах. - М.: Транспорт, 1976. - 271 с.

3. ВСН 26-90 Инструкция по проектированию и строительству автомобильных дорог нефтяных и газовых промыслов Западной Сибири. - М.: СоюзДорНИИ, 1991. - 152 с.

4. Пособие по проектированию земляного полотна автомобильных дорог на слабых грунтах (к СНИП 2.05.02-85). - М.: СоюзДорНИИ Митрансстроя СССР, 1989. - 191 с.

5. ВСН 2-105-78. Инструкция по строительству временных дорог для трубопроводного строительства в сложных условиях (на обводненной и заболоченной местности). - М.: Миннефтегазстрой, 1978. - 116 с.

6. Пшеничникова Е.С. Особенности применения геосинтетических материалов в зоне вечной мерзлоты // Дороги. Инновации в строительстве. - 2018. - № 67. - С. 28-31.

7. Федоренко Е.В. Оценка устойчивости армогрунтовых сооружений // Дороги. Инновации в строительстве. - 2019. № 75. - С. 50-53.

8. Мухамеджанов Г.К. О методах испытаний геосинтетических материалов // Дороги. Инновации в строительстве. - 2011. № 7. - С. 31-35.

9. Бондарева Э.Д. Особенности проектирования армогрунтовых конструкций в дорожном строительстве // Дороги. Инновации в строительстве. - 2014. - № 34. - С. 36-38.

10. Егоров А.В. Расчетный анализ укрепления насыпей на слабых основаниях с использованием армирующей геоплатформы // Дороги. Инновации в строительстве. - 2015. - № 43. - С. 31-33.

11. Устян Н.А., Мариненко Д.В. Измерение осадок земляного полотна на участках оснований из слабых грунтов с применением принципов инклинометрии при реконструкции и строительстве автомобильных дорог общего пользования // Дороги России XXI века. - 2020. - № 3. - С. 77-81.
12. Sari P.T.K., Wardani M.K Combined effects of vertical drain and pre-loading to reduce the number of geotextile reinforcement for road embankment design // Journal of Physics: Conference Series. -2020 . - V. 2. - P. 81-93.

13. Bearing capacity of geocell reinforcement in embankment engineering / L. Zhang, M. Zhao, C. Shi, H. Zhao // Geotextiles and Geomembranes. - 2010. - V. 28. - Iss. 5. - P. 475-482.

14. Yun-min C., Wei-ping C., Ren-peng C. An experimental investigation of soil arching within basal reinforced and unreinforced piled embankments // Geotextiles and Geomembranes. - 2008. V. 26. - Iss. 2. - P. 164-174.

15. A case study on geogrid-reinforced and pile-supported widened highway embankment / W. Lu, L. Miao, F. Wang, J. Zhang, Y. Zhang, H. Wang // Geosynhthetics International. - 2020. V. 27. - Iss. 3. - P. 261-274

16. Modeling humidity and stress-dependent subgrade soils in flexible pavements / J. Peng, J. Zhang, J. Li, Y. Yao, A. Zhang // Computers and Geotechnics. - 2020. - V. 120. - P. 153-162.

17. Aleksandrov A., Dolgih G., Ralinin A. Calculation of shear stresses in the soil of the subgrade using empirical plasticty conditions // Journal of Physics: Conference Series. - 2020. - V. 2. - P. 71-82.

18. Point Foundation (PF) method for foundations and embankments / Anh Ngoc Nguyen, Tien Dung Nguyen, Chul Soon Yim, Myrong Seok Lee // Geotechnics for Sustainable Infrastructure Development. - 2019. - V. 62. - P. 571-578.

19. Berrabah F., Benmebarek S., Benmebarek N. Three-dimensional numerical analysis of geosynthetic-reinforced embankment over locally weak zone // Transportation Infrastructure Geotechnology. - 2020. - V. 7. - P. 269-296.

20. Simulation of sequential construction of embankments on reinforced soft clay foundation / M. Gaber, A. Kasa, N. AbdulRahman, J. Alsharef // Indian Geotechnical Journal. - 2019. V. 49. - P. 224-231.

Поступила 10.03.2021 2.

\section{Информация об авторах}

Eременко $\boldsymbol{E} . \boldsymbol{C}$., ведущий инженер Отдела развития технологий инженерных изысканий и проектирования ООО «НК «Роснефть»-НТЦ».

Галич Н.H., главный специалист Отдела развития технологий инженерных изысканий и проектирования ООО «НК «Роснефть»-НТЦ».

Кузьмин Д.А., генеральный директор ООО «НК «Роснефть»-НТЦ».

Мелентьев А.С., заместитель генерального директора по технологическому развитию ООО «НК «Роснефть»-НТЦ». 
UDC 625.71 .8

\title{
REINFORCING THE BULK OF INNER-FIELD VEHICLES ON A WEAK BASE AS A DECISION TO REDUCE THE SIZE OF THE DRAIN OF THE SUBGRADE
}

\author{
Evgeniy S. Eremenko ${ }^{1}$, \\ eseremenko@rnntc.ru
}

Nicolay N. Galich 1 , nngalich@rnntc.ru

Dmitri A. Kuzmin ${ }^{1}$, dakuzmin@rnntc.ru

\author{
Alexander S. Melentiev1, \\ asmelentev@rnntc.ru \\ 1000 «NK «Rosneft»-NTC», \\ 54, Krasnaya street, Krasnodar, 350000, Russia.
}

The relevance of the research is caused by the need to build an earthen bed, including an earthen bed of intra-field roads on the territory of NK Rosneft PJSC, in difficult engineering and geological conditions. At the same time, the total length of roads is several thousand kilometers. It is also necessary to note the emergence of a huge assortment of geotextile reinforcing materials, the use of which is a modern effective way to solve the problem of improving the reliability of earthworks, including the issue of reducing the precipitation of embankments of the earthwork, which should lead to optimization of funds by reducing the volume of earthworks.

The main aim of the research is to optimize capital expenditures for the construction of intra-field roads on a weak base due to reinforcement of embankments with local (lay flooring) or geosynthetic materials.

Object: soil embankment.

Subject: sedimentary phenomena of the soil of the earth on a weak base, depending on the type of fortification.

Methods: retrospective analysis and comparison method. The precipitation was calculated by layer-by-layer summation, and a graphoanalytic method was used to determine the final precipitation $S_{k o n}$ and the calculated load $P$. To calculate the settlement of the embankment, taking into account the reinforcement of the roadbed with a sunbed or geo-nut, a mathematical modeling method was also used.

Results. The paper introduces the calculations of substantiation of perspective of applying the alternative materials at strengthening roadbed on weak base. To confirm the cost-effectiveness of the proposed solutions, a technical and economic comparison of two options for reinforcing the structure of the roadbed was made: a bed flooring and a geo-nut - with a model without reinforcement. The economic effect of using the reinforcement of the roadbed on a weak base was determined.

\section{Key words:}

Subgrade, subgrade reinforcement structures, lay flooring, geogrid, maximum stress, degree of embankment stability, final embankment settlement.

\section{REFERENCES}

1. Semendyaev L.I. Metodika rascheta nasypey, armirovannykh razlichnymi materialami [Procedure for calculation of embankments reinforced with various materials]. Bronnicy, UNR-494, $2001.46 \mathrm{p}$

2. Evgenev, I.E., Kazarnovskiy, V.D. Zemlyanoe polotno avtomobilnykh dorog na slabykh gruntakh [Grave surface of roads on weak soils]. Moscow, Transport Publ., 1976. 271 p.

3. VSN 26-90 Instruktsiya po proektirovaniyu i stroitelstvu avtomobilnykh dorog neftyanykh $i$ gazovykh promyslov Zapadnoy Sibiri [Departmental Building Codes 26-90. Instructions for the design and construction of highways for oil and gas fields in Western Siberia]. Moscow, SoyuzDorNII Publ., 1991. 152 p.

4. Posobie po proektirovaniyu zemlyanogo polotna avtomobilnykh dorog na slabykh gruntakh ( $k$ SNIP 2.05.02-85) [Manual for the design of roadways on weak soils (to Building Regulations 2.05.02-85]. Moscow, SoyuzDorNII Mitransstroya SSSR Publ., $1989.191 \mathrm{p}$.

5. VSN 2-105-78. Instruktsiya po stroitelstvu vremennykh dorog dlya truboprovodnogo stroitelstva $v$ slozhnykh usloviyakh (na obvodnennoy $i$ zabolochennoy mestnosti) [Departmental Building Codes 2-105-78. Instructions for construction of temporary roads for pipeline construction in difficult conditions (in watered and wetland areas)]. Moscow, Minneftegazstroy Publ., 1978. 116 p.

6. Pshenichnikova E.S. Osobennosti primeneniya geosinteticheskikh materialov v zone vechnoy merzloty [Features of application of geosynthetic materials in permafrost zone]. Dorogi. Innovatsii $v$ stroitelstve, 2018, no. 67, pp. 28-31.
7. Fedorenko E.V. Otsenka ustoychivosti armogruntovykh sooruzheniy [Stability assessment of armogrunt structures]. Dorogi. Innovatsii v stroitelstve, 2019 , no. 75 , pp. 50-53.

8. Mukhamedzhanov G.K. O metodakh ispytaniy geosinteticheskikh materialov [On methods of testing geosynthetic materials]. Dorogi. Innovatsii v stroitelstve, 2011, no. 7, pp. 31-35.

9. Bondareva E.D. Osobennosti proektirovaniya armogruntovykh konstruktsy $\mathrm{v}$ dorozhnom stroitelstve [Design features of armogrunt structures in road construction]. Dorogi. Innovatsii $v$ stroitelstve, 2014, no. 34, pp. 36-38.

10. Egorov A.V. Raschetny analiz ukrepleniya nasypey na slabykh osnovaniyakh $\mathrm{s}$ ispolzovaniem armiruyushchey geoplatformy [Design analysis of reinforcement of embankments on weak bases using reinforcing geoplatform]. Dorogi. Innovatsii v stroitelstve, 2015, no. 43, pp. 31-33.

11. Ustyan N.A., Marinenko D.V. Izmerenie osadok zemlyanogo polotna na uchastkakh osnovaniy iz slabykh gruntov s primeneniem printsipov inklinometrii pri rekonstruktsii i stroitelstve avtomobilnykh dorog obshchego polzovaniya [Measurement of soil sediment on sections of bases from weak soils using the principles of inclinometry during reconstruction and construction of public roads]. Dorogi Rossii XXI veka, 2020, no. 3, pp. 77-81.

12. Sari P.T.K., Wardani M.K. Combined effects of vertical drain and pre-loading to reduce the number of geotextile reinforcement for road embankment design. Journal of Physics: Conference Series, 2020, vol. 2, pp. 81-93.

13. Zhang L., Zhao M., Shi C., Zhao H. Bearing capacity of geocell reinforcement in embankment engineering. Geotextiles and Geomembranes, 2010, vol. 28, no. 5, pp. 475-482. 
14. Yun-min C., Wei-ping C., Ren-peng C. An experimental investigation of soil arching within basal reinforced and unreinforced piled embankments. Geotextiles and Geomembranes, 2008, vol. 26 , Iss. 2, pp. 164-174.

15. Lu W., Miao L., Wang F., Zhang J., Zhang Y., Wang H. A case study on geogrid-reinforced and pile-supported widened highway embankment. Geosynhthetics International, 2020, vol. 27, no. 3, pp. 261-274.

16. Peng J., Zhang J., Li J., Yao Y., Zhang A. Modeling humidity and stress-dependent subgrade soils in flexible pavements. Computers and Geotechnics, 2020, vol. 120, pp. 153-162.

17. Aleksandrov A., Dolgih G., Ralinin A. Calculation of shear stresses in the soil of the subgrade using empirical plasticty conditions. Journal of Physics: Conference Series, 2020, vol. 2, pp. 71-82.
18. Anh Ngoc Nguyen, Tien Dung Nguyen, Chul Soon Yim, Myrong Seok Lee Point Foundation (PF) method for foundations and embankments. Geotechnics for Sustainable Infrastructure Development, 2019, vol. 62, pp. 571-578.

19. Berrabah F., Benmebarek S., Benmebarek N. Three-dimensional numerical analysis of geosynthetic-reinforced embankment over locally weak zone. Transportation Infrastructure Geotechnology, 2020, vol. 7, pp. 269-296.

20. Gaber M., Kasa A., Abdul-Rahman N., Alsharef J. Simulation of sequential construction of embankments on reinforced soft clay foundation. Indian Geotechnical Journal, 2019, vol. 49, pp. 224-231.

Received: 10 March 2021.

\section{Information about the authors}

Evgeniy S. Eremenko, lead engineer, OOO «NK «Rosneft»-NTC».

Nicolay N. Galich, chief specialist, OOO «NK «Rosneft»-NTC».

Dmitri A. Kuzmin, general manager, OOO «NK «Rosneft»-NTC».

Alexander S. Melentiev, deputy general manager, OOO «NK «Rosneft»-NTC». 